\title{
Texas Biology and Biological Anthropology Faculty Express Their Views on Teaching Evolution
}

\author{
Shelley L. Smith • Raymond A. Eve
}

Published online: 29 October 2009

(C) Springer Science + Business Media, LLC 2009

\begin{abstract}
Unsurprisingly, survey results indicate that Texas biology and biological anthropology faculty with expertise in an evolutionary area strongly support teaching "just evolution" $(100 \% ; N=54)$ and not creationism/intelligent design. Importantly, they do not think that religious faith is incompatible with acceptance of evolutionary biology $(91 \% ; N=55)$, even though $50 \%(N=52)$ describe themselves as "not at all religious." As school boards nationwide debate science standards, it is important that faculty with relevant expertise have a voice. Biological anthropologists should not be overlooked as a public resource in these debates.
\end{abstract}

Keywords Science education · Science curriculum .

Science standards $\cdot \mathrm{K}-12$

In the spring of 2008, anticipating debate over the K-12 science curriculum, the Texas Freedom Network Education Fund (TFNEF) sponsored a statewide survey of Texas collegiate biology and biological (aka physical) anthropology faculty regarding their opinions of student preparedness for classes and their thoughts on teaching evolution. The positive results (in the judgment of the current authors) from the survey of 464 respondents are available in the report by Eve and Belhadi (2008). Given speculation regarding what scientists believe, TFNEF felt it important to let these scientists speak for themselves. This is particularly important because one of the common social movement tactics of the current anti-evolutionists is to argue that "lots" of qualified faculty members reject evolution and are being

S. L. Smith $(\bowtie) \cdot R$. A. Eve

Department of Sociology and Anthropology,

University of Texas at Arlington,

Box 19599, Arlington, TX 76019, USA

e-mail:slsmith@uta.edu forcibly hushed up or even expelled from the academy. For example, witness the nationally released film hosted by business commentator Ben Stein. Its title, "Expelled," derived from the film's central thesis that scientists were being expelled from their positions for openly opposing evolution (the film was grievously disingenuous, as can be seen by visiting www.expelledexposed.com).

Although all of modern biology is evolutionary in its focus, for purposes of the report presented here, we examine only the 57 respondents who chose an expertise that would place them routinely at the center of evolutionary studies. Thirty-six individuals (63.2\%) chose simply "Evolution" as their focus. The second highest category, selected by 14 individuals, was Paleoanthropology/Human Evolution (24.6\%). The remainder of subjects identified their primary area as Evolutionary Developmental Biology $(N=3)$, Population Genetics $(N=2)$, Evolutionary Psychology/ Socioecology $(N=1)$, or Primate Evolution $(N=1)$.

In response to the question, "Have you taught a course that included a substantial block of material on human evolution?" 44 of 56 respondents indicated that they had done so within the past five years, and an additional four had done so but not within the past five years. Of these 48 respondents, 27 had taught undergraduates and 21 had taught human evolution to both undergraduate and graduate students. It is important to note that $86 \%$ of the respondents have taught human evolution, which is, of course, the area of evolutionary studies that creates the most pre-collegiate educational controversy and anxiety.

\section{Demographic Characteristics: Political and Religious Views}

Sixteen respondents are female and 41 are male. Educationally, 56 of the 57 have a Ph.D. or Sc.D. degree. Twelve 
are located at the University of Texas at Austin, and six each are from the main campuses of Texas A\&M and the University of Houston. All other schools are represented by four or fewer individuals. Experience in teaching ranges widely, from $23 \%$ who have taught zero to five years to $7 \%$ who have taught more than 35 years. Years lived in Texas similarly shows a large range, from 15 who have been in the state five years or fewer to nine who have lived in Texas over 35 years. Fourteen subjects have taught in Texas for over 20 years.

Politically, these individuals are a liberal group (Fig. 1). On particular issues, the sums of extremely or very conservative vs. extremely or very liberal replies are distributed as follows: gun control, 3 vs. 30; legalizing abortion, 3 vs. 44; and pro-environmentalism, 1 vs. 43 (abortion is, of course, already legal!).

For religion, these individuals are on average strikingly less religious than the general US population. Of the 52 responding, five describe themselves as "very religious," nine as "somewhat religious," 12 as "not very religious," and $26(50 \%)$ as "not at all religious." Sixteen respondents list their religious preference as Christian, 11 identify as agnostic, and 13 report being atheists. Twenty-two respondents state that they never attend religious services, as opposed to nine who attend more than once per month. Responses to specific God and Bible questions are given in Table 1. Note that, in response to the seemingly simple statement, "I believe in God," 19 strongly disagree vs. ten who strongly agree (Fig. 2).

Twenty-one of 51 strongly agreed that "Religion is not very helpful in solving the major problems that face us today," as opposed to five who strongly disagreed. However, when asked if it is the case that neither religion nor science is of much help in solving important problems, 36 of 53 strongly disagreed, 12 disagreed somewhat, and none agreed strongly. We also found that 51 of 52 respondents strongly disagreed that "Teaching evolution leads to social problems" (one person was not sure). Interestingly, when asked, "Do you believe that evolution is a valid theory AND that evolution will lead humans eventually to a higher state and/or a closer union with God?" five respondents said yes and 12 said possibly while 34 said no. Since teleology is denied by modern evolutionary theory, the "yes" and "possibly" answers would appear to be related to individual religious or spiritual beliefs.

\section{Student Preparedness}

Survey participants were asked to rank, on a scale of 1 (not important) to 5 (very important), how important it is that incoming college students be better prepared than they currently are in 17 subject areas. Summing percentages for 4's and 5's (important and very important), the three academic skill areas judged to be in need of the greatest improvement are English and Writing, Logic and Critical Thinking Skills, and the Scientific Method (evidence, hypothesis testing, and theory); these three areas tied at 92.7\%. Evolutionary Theory, Evolutionary Mechanisms, and Genetics closely followed (Fig. 3). When asked about overall preparedness of incoming college students taking their classes, 30 of $54(55.6 \%)$ thought preparedness had remained the same since they began teaching, and 21 $(38.9 \%)$ thought it had declined; only three $(5.6 \%)$ thought it had improved.

Fig. 1 Political persuasion

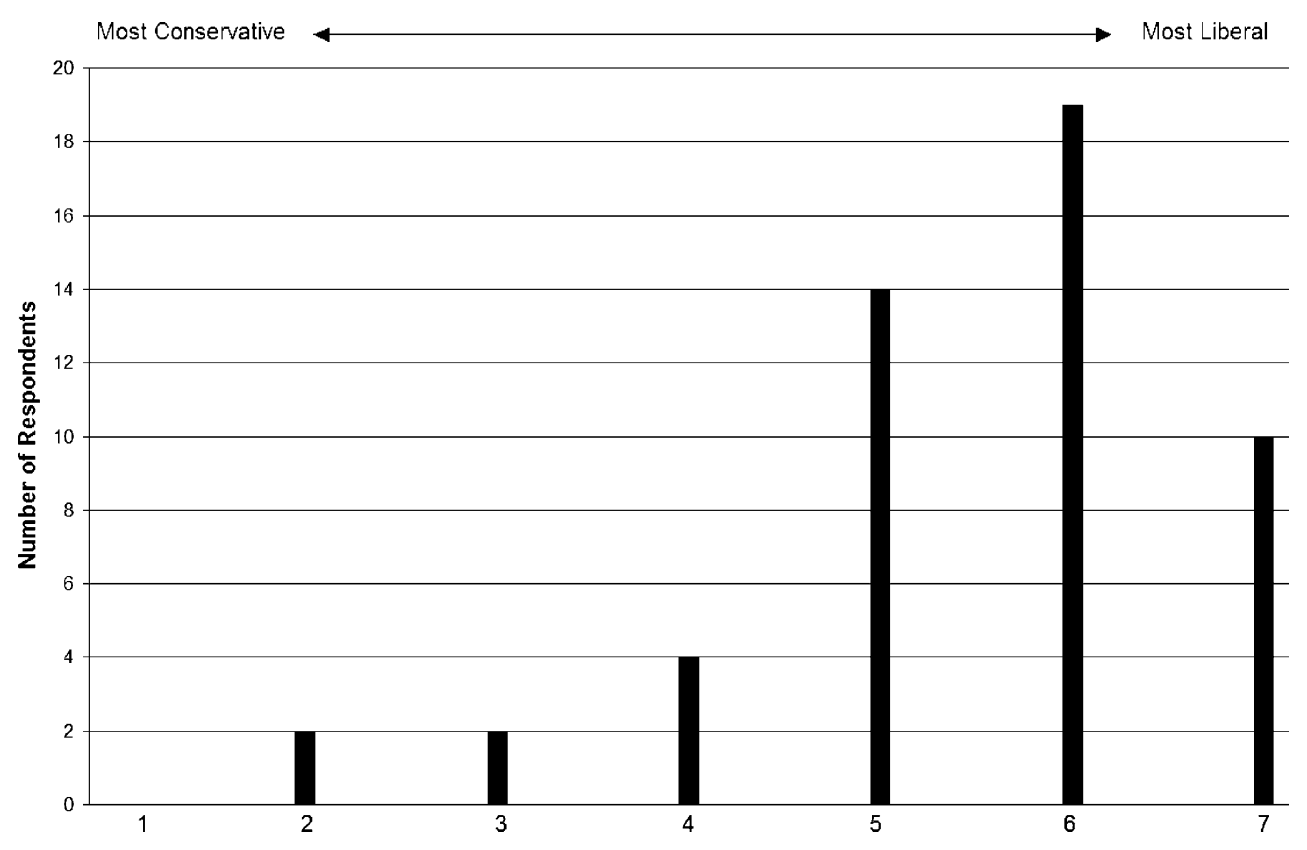


Table 1 God and Bible responses ("Don't Know" and No Response coded as missing)

\begin{tabular}{|c|c|c|c|c|c|}
\hline \multicolumn{2}{|l|}{ Agree } & \multirow[t]{2}{*}{ Not sure } & \multicolumn{2}{|l|}{ Disagree } & \multirow[t]{2}{*}{$N$} \\
\hline Strongly & Somewhat & & Somewhat & Strongly & \\
\hline \multicolumn{6}{|c|}{ I believe in a personal God with whom I can communicate. } \\
\hline 4 & 4 & 5 & 5 & 33 & 51 \\
\hline \multicolumn{6}{|c|}{ I believe in a God who takes an active role in the lives of people living in this world today. } \\
\hline 5 & 1 & 4 & 4 & 37 & 51 \\
\hline \multicolumn{6}{|c|}{ I believe in God. } \\
\hline 10 & 2 & 8 & 8 & 19 & 47 \\
\hline \multicolumn{6}{|c|}{ I think of myself as a religious fundamentalist. } \\
\hline 0 & 1 & 1 & 1 & 49 & 52 \\
\hline \multicolumn{6}{|c|}{ The Bible is the literal Word of God and everything happened or will happen exactly as it says in the Bible. } \\
\hline 0 & 0 & 0 & 2 & 50 & 52 \\
\hline \multicolumn{6}{|c|}{ The Bible has the answers to all important human problems. } \\
\hline 1 & 2 & 2 & 6 & 41 & 52 \\
\hline
\end{tabular}

\section{Challenges to Teaching Evolution}

When asked how many students confronted them in an average semester with challenges grounded in creationism or intelligent design, 20 respondents said none, 26 said one or two, and ten said more than two. When asked if they had ever been lobbied by students to include creationist or intelligent design materials, respectively, in classes, 40 and 43 said never, 12 and ten said once or twice, and four and three said they had been so lobbied more than twice (Fig. 4). Thus, it appears that challenges professors recognize as coming from creationist/intelligent design sources are encountered more frequently than direct student lobbying to change course content. Professors seem to receive questions, comments, and challenges more frequently than they are "pushed" to include alternate materials.

\section{Educator's Views of Evolution and Teaching Evolution}

Not surprisingly, biologists and biological anthropologists who teach evolution do not advocate teaching creationism or intelligent design as valid science! When asked if these two are significantly different, four said yes, 50 said no, and one person was not sure. The majority therefore apparently sees intelligent design as just repackaged creationism.

Respondents were asked to what extent they agreed that certain perspectives should be "presented in public school science classrooms as scientifically credible." Choices were (1) Young Earth Creationism (i.e., earth $<10,000$ years old; species created as they are today), (2) Old Earth Creationism (i.e., ancient earth; evolution within narrow/divinely ordained limits only), and/or (3) Intelligent Design (i.e., intervention by intelligent agent in creation/evolution of life). Regarding Young Earth Creationism, all 54 who responded said they strongly disagreed. For Old Earth Creationism, of 55 responding, 54 strongly disagreed and one disagreed somewhat. For Intelligent Design, all 55 who responded strongly disagreed.

Another set of questions aimed to assess professors' opinions about the presentation of supposed "weaknesses" of evolution. This section was prefaced by the following text:

A major topic of concern for the Texas State Board of Education will be the question of whether or not to mandate that biology teachers cover the "strengths and weaknesses" of evolution. This phrasing is often advocated by proponents of creationism and intelligent design (like the Discovery Institute ${ }^{[1]}$ ), who wish to emphasize what they regard as a "more balanced view" of evolutionary theory.

\footnotetext{
${ }^{1}$ The Discovery Institute is the latest, and likely the most currently potent, of anti-evolution social movement organizations. From 1972 until recently, this position was held by the Institute for Creation Research, located for most of that time in Santee, CA, but recently relocated to Dallas, TX. Much of the ICR's agenda promoted the socalled Young Earth Creationism (YEC). A sea change, however, began in 1989, when the Foundation for Thought and Ethics of Richardson, Texas, published Of Pandas and People, the first textbook to promote the concept of "intelligent design." In recent years, however, the handsomely funded Discovery Institute that is located on the edge of Seattle has easily taken the crown for promotion of anti-evolutionism. The Discovery Institute is a rightwing Christian think tank that wishes to expand the definition of science per se to include a certain degree of supernatural causation. The Institute has begun handing out substantial grant money to academics for research and conferences promoting "intelligent design." They hope thereby to crack the barrier of almost no peerreviewed publications to date. The Institute is funded largely by wealthy businessmen, most notable among whom is Howard F. Ahmanson, Jr.
} 
Fig. 2 I believe in God

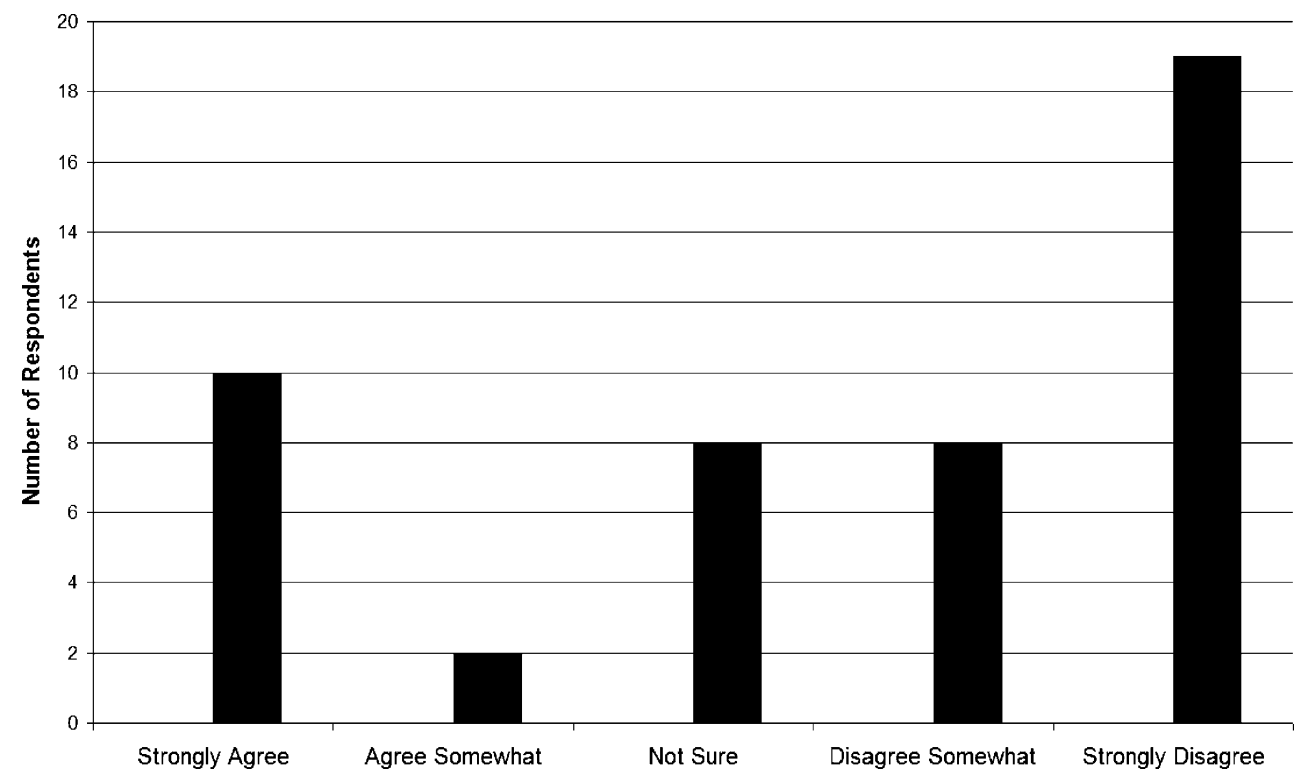

Respondents were first asked to indicate the extent to which they agreed that these "weaknesses" represent "valid scientific objections to evolution." Fifty-four of 55 who answered said that they strongly disagreed, while the last did not know. In response to the strong proposition that the Board of Education "should amend curriculum standards to exclude discussion of "weaknesses' of evolution as advanced by proponents of creationism and intelligent design" (emphasis in survey), 42 of 54 strongly agreed and three more agreed somewhat. (Of course, one should realize that some of those desiring discussion might want this in order to argue that these views are non-scientific or that the supposed "weaknesses" are not valid objections.) In contrast to their answers to the above questions, the majority of subjects was open to encouraging discussion in high school classrooms of "areas of genuine uncertainty and active research within the scientific community regarding evolution (e.g., whether speciation can occur sympatrically, neutral theory, punctuated equilibrium)" (Fig. 5). Thus, it seems clear that a large number of sample respondents were quick to recognize certain "coded language" favored by anti-evolution social movement organizations and were quick to distinguish this
Fig. 3 Students should be better prepared than they are (important+very important) in

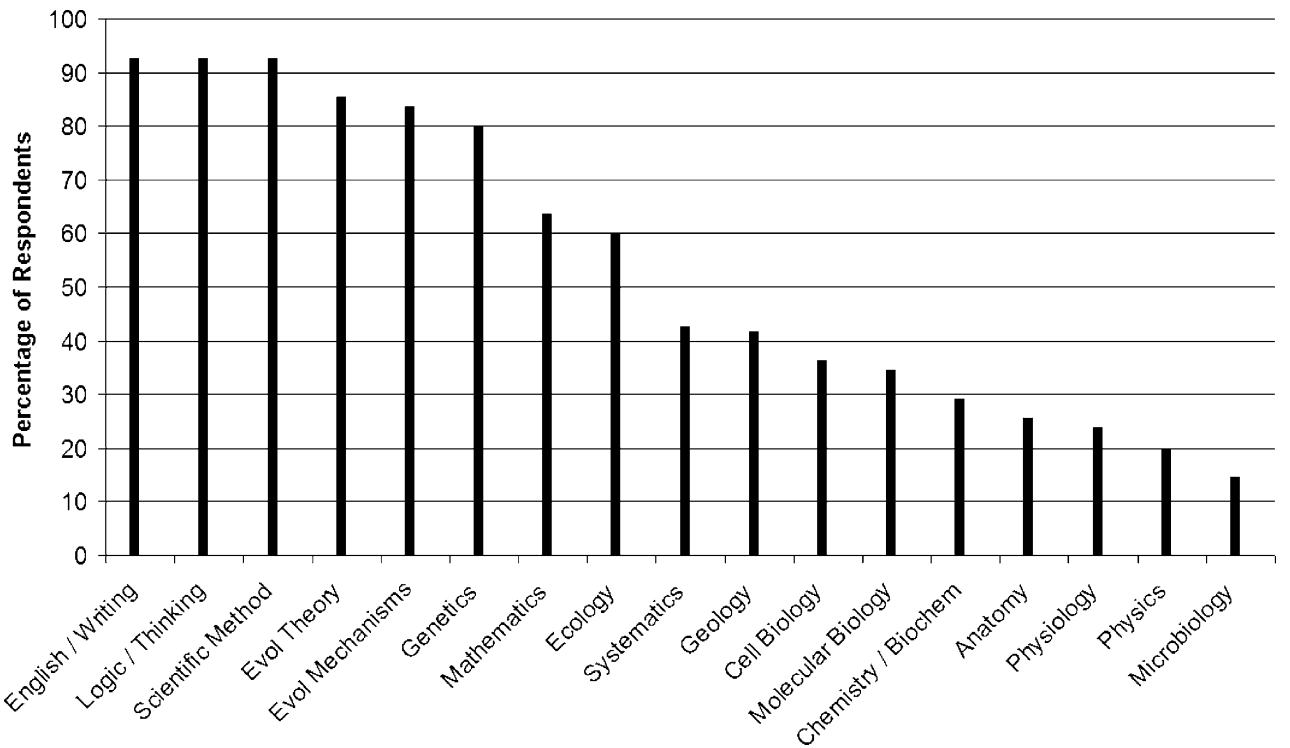


Fig. 4 Ever lobbied to include Creationist/I.D. materials?

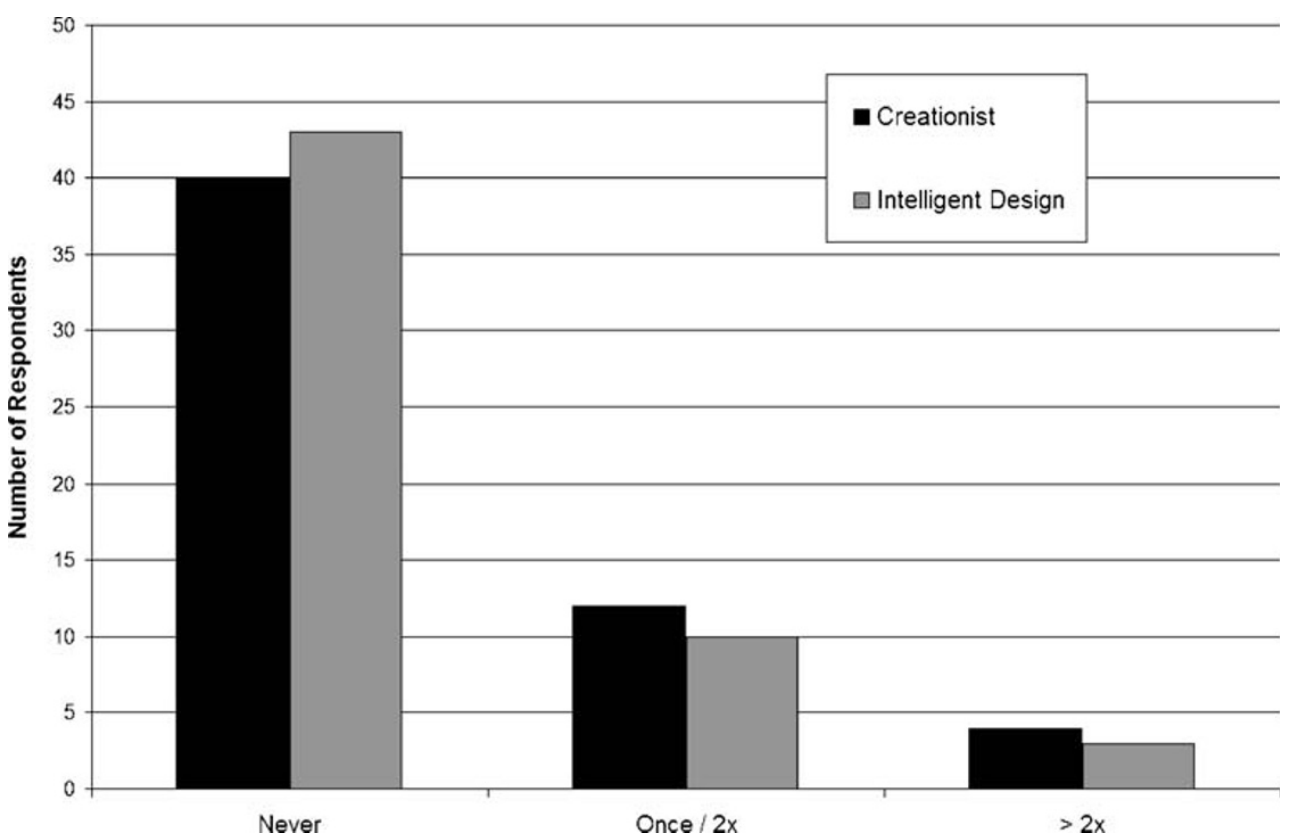

from legitimate debate with qualified colleagues. The fact that Logic and Critical Thinking Skills tied for Rank 1 as needing improvement among beginning college students (see above) supports this interpretation.

In response to questions probing whether faculty felt that teaching high school students the so-called "weaknesses" as scientifically valid objections would impair their readiness for college or ability to compete for jobs, 41 of 53 strongly agreed and a further six agreed somewhat that preparation for college would be impaired; 31 of 54 strongly agreed and 13 agreed somewhat that competitive ability for twenty-first century jobs would be impaired.

\section{The Big Questions}

Professors were asked which of the following "most closely mirrors your view of evolutionary biology." Choices were the following:

(a) Modern evolutionary biology is largely correct in its essentials, but still has open questions for active scientific research.

(b) Modern evolutionary biology is correct in some respects. While further scientific research will require some major alterations to current theory, these
Fig. 5 Discuss "areas of genuine uncertainty and active research"?

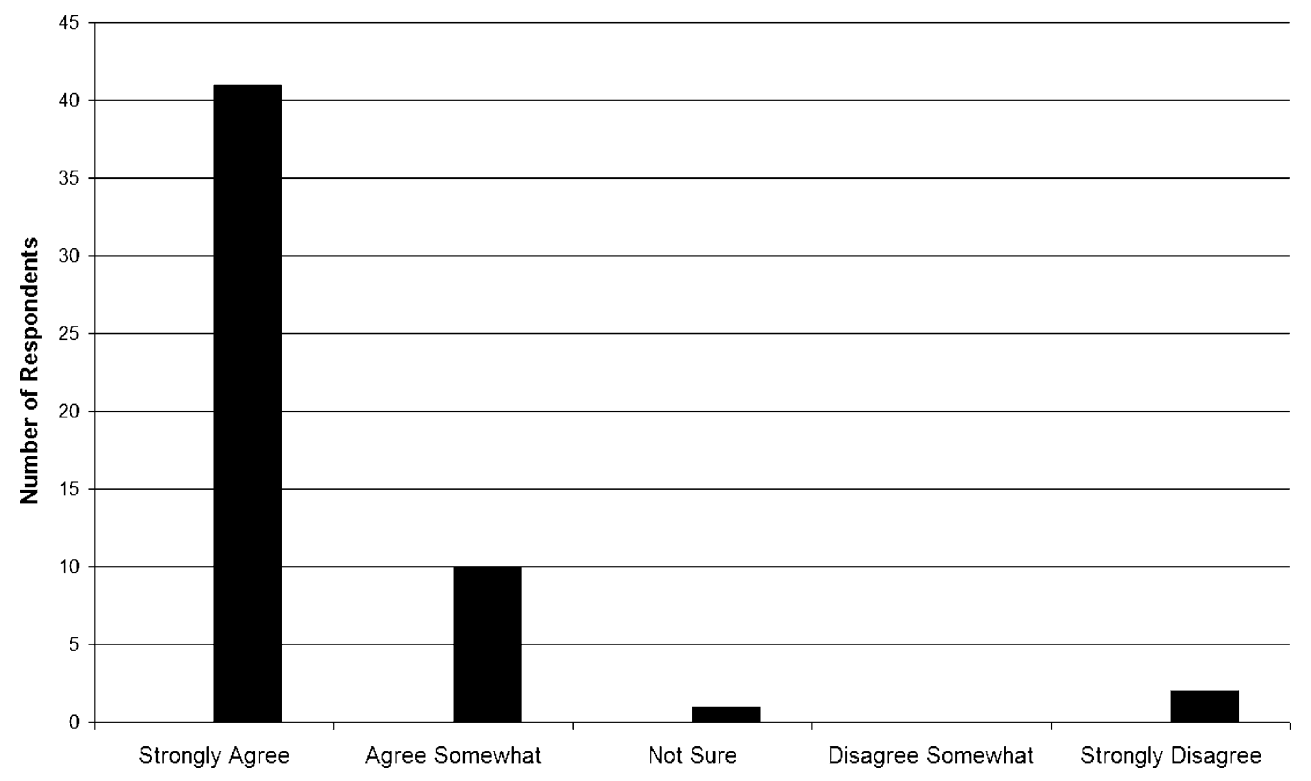


advances will not invoke intervention by any supernatural agent.

(c) Modern evolutionary biology is right about the common ancestry of all extant organisms, but it is necessary to supplement it by invoking periodic intervention by an intelligent designer.

(d) Modern evolutionary biology is mostly wrong. Life arose through multiple creation events by an intelligent designer, although evolution by natural selection played a limited role.

(e) Modern evolutionary biology is completely wrong. Life was created essentially as we see it today.

Fifty-one of 55 respondents (92.7\%) chose the first statement above, and a further four respondents (7.3\%) chose the second position. No respondent selected answers $\mathrm{c}$, d, or e as shown above.

On the compatibility of science and religious faith, results were strongly supportive. Asked if they agreed that "It is possible for someone who accepts evolutionary biology to have religious faith," 41 of 55 (74.5\%) strongly agreed and nine (16.4\%) agreed somewhat (Fig. 6). Therefore, even for most of those who do not themselves profess religious faith (see above), respondents do not think that people must choose either to accept scientifically verified theory or religious faith.

Finally, it is very clear that these professors do not desire to introduce creationism or intelligent design to their students. As evidence for this, we can note that, when asked, "If it were solely up to you, would you prefer to teach: a) just evolution; b) just creationism/intelligent design as a valid account of origins; or c) both?" all respondents $(N=54)$ marked "just evolution."

\section{Conclusion}

The results of this survey are unlikely to startle many readers of this journal. We know that biologists and biological anthropologists accept the main tenets of evolutionary theory, even if they argue endlessly about the details. We also know that evolutionary scientists are on the whole politically liberal and tend not to attend religious services, even those who live in Texas. We generally do not ask these individuals whether they believe in God, but we know (or strongly suspect) many do not. In some ways, the results of this survey align remarkably with the worst fears of politically conservative religious fundamentalists. The "culture war" over human origins exists for quite real reasons. However, there is to date no good evidence that studying evolutionary biology leads a person to be liberal (on the majority of issues at least) or nonreligious. It is equally plausible, and perhaps more likely, that those drawn to evolutionary biology as a career had these tendencies before embarking on this career path. What is most salient here is the near unanimity that "just evolution" is the proper teaching choice and the almost $90 \%$ agreement that modern evolutionary biology is not incompatible with religious faith.

Whatever our views on private personal matters, the survey results presented here should help to bolster the conviction that our children and young adults deserve to be taught universally accepted scientific principles and theory. Nine out of ten evolutionary biologists surveyed further claim that what they teach is compatible with religious belief. Will the public believe them? Is presenting results such as those seen above all we need to do to provide reassurance on this hot-button issue?
Fig. 6 It is possible for someone who accepts evolutionary biology to have religious faith

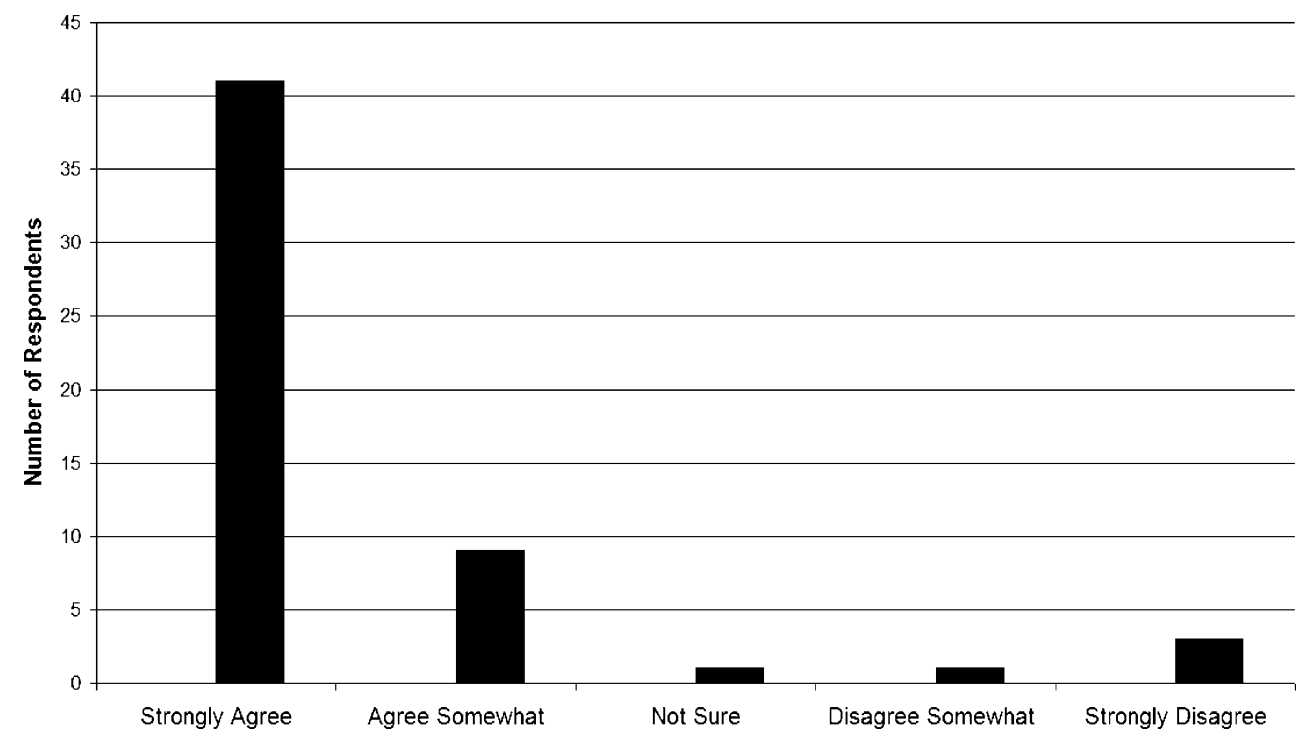


While we consider these survey results encouraging, there is reason for continued concern. Results of the full survey of 464 respondents were available to the Texas State Board of Education during the debates in March 2009 over the state's science standards. A press release from the National Center for Science Education (2009) details the mixed results of the final votes: "The board majority amended the Earth and Space Sciences standards as well as the Biology standards (TEKS) with loopholes and language that make it even easier for creationists to attack science textbooks....Although the 'strengths and weaknesses' wording that has been part of the standards for over a decade was finally excised-wording that has been used to pressure science textbook publishers to include creationist arguments - a number of amendments put the creationistinspired wording back in." Dr. Eugenie Scott, the Executive Director of NCSE, is quoted as saying "This is a setback for science education in Texas, not a draw, not a victory. The revised wording opens the door to creationism in the classroom and in the textbooks. The decisions will not only affect Texas students for the next ten years, but could result in watered-down science textbooks across the U.S. There's a reason creationists are claiming victory."

Lest you who reside outside Texas think what happens in the Lone Star State need not concern you, as the quote above indicates, Texas, along with California and Florida, is a major player in the pre-collegiate textbook market. As Tamin Ansary, a former textbook editor, says, "Texas rules" among the Big Three because it allocates dedicated funding to textbooks and because it has an adoption process extending through 12 th grade. What "Texas wants" is "what the entire nation will therefore get" (Ansary 2004).
As public debate continues, we encourage pre-collegiate teachers and other concerned citizens to seek the expertise of both biologists and biological anthropologists. Many readers may not realize that the NCSE Director quoted above, Dr. Eugenie Scott, received her Ph.D. training in biological anthropology. Human and nonhuman primate evolution is often taught in anthropology departments by biological anthropologists rather than in biology departments by biologists. A biological anthropology professor from Southern Methodist University, Dr. Ronald K. Wetherington, is the 2009 recipient of the Texas Freedom Network's Grassroots Hero Award in recognition of his efforts in evaluating and publicly discussing new Texas science curriculum standards. Acknowledging that human evolution is what makes many uneasy, it would be wise to consult the experts in this arena. Those advocating improved science education should not overlook this key resource.

Acknowledgements We thank our survey participants for their time investment, Chawki Belhadi for data management, and TFNEF for funding the survey.

\section{References}

Ansary T. A textbook example of what's wrong with education. Edutopia, November. www.edutopia.org/muddle-machine; 2004.

Eve RA, Belhadi CA. Evolution, creationism and public schools: surveying what Texas scientists think about educating our kids in the 21 st century. www.tfn.org; 2008.

Science setback for Texas schools 2009. National Center for Science Education (NCSE) press release, March 30. ncseweb.org. 